\title{
Impact of Covid-19 on the Creative Industries in Slovakia: Evaluation and Elimination
}

\author{
Helena Majduchova ${ }^{1}$, and Maria Kmety Bartekova ${ }^{1, *}$ \\ ${ }^{1}$ University of Economics in Bratislava, Faculty of Business Management, Dolnozemska cesta 1, \\ 85235 Bratislava, Slovakia
}

\begin{abstract}
Research background: The restrictions pose a threat to the creative industries, as some companies and self-employed persons suffer major losses. Many freelancers and micro-enterprises work in the creative industries. They depend more than others on events and markets for earning money. The 33288 employees that comprise the CIs are therefore hit particularly hard by COVID- 19 .

Purpose of the article: The aim of the paper is to measure the Covid-19 impacts on the Creative industries in Slovakia and evaluate the economic compensation suffered from Ministry of Culture of the Slovak Republic. The compensation payments consist of a certain percentage of the income from the year 2019 and encompass business expenses such as rent and other fixed costs.

Methods: Our calculations on the extent to which the creative industries (CIs) and its sub-markets are affected by the COVID-19 pandemic are based on data from Ministry of Culture of the Slovak Republic, the Statistical Office of the Slovak Republic and the FINSTAT database for the year 2019 and 2020.

Findings \& Value added: The effects of the ordered closures and the associated effects in the individual sub-sectors and occupational fields are estimated. For this reason, economic effects are calculated and recorded based on a scenario analysis. In a second step, the international perspective on the COVID-19 pandemic will be considered. Overall, the analysis of the consequences of the pandemic for the creative industries is intended to provide an overview of the possible consequences in the creative industries and, together with the knowledge about the procedures in other countries, to make political action needs more clearly recognisable.
\end{abstract}

Keywords: Creative industries; Covid-19; Grants; Income approach

JEL Classification: $O 15 ; Z 10 ; Z 18$

\footnotetext{
*Corresponding author: maria.bartekova@euba.sk
} 


\section{Introduction}

National and local governments across the globe have introduced multiple measures that support workers and enterprises in light of COVID-19 (Bartik et al., 2020, Beland et al., 2020, Krajnovic et al., 2021). Many of them, particularly those not targeted to CI, are not well suited to the peculiarities of the sector. Employment and income support measures are not always accessible or adapted to the new and non-standard forms of employment (freelance, intermittent, hybrid- e.g. combining salaried, part-time work with freelance work) that tend to be more precarious and are more common in CI (McKibbin and Roshen, 2021, Palrao et al., 2021). SME finance measures could also be better adapted to businesses based on intangible assets (Pankov et al., 2021, Mont et al., 2021). Similarly, innovation supports, largely catering to technological innovations, could be adapted to other forms of innovation more common in CI, such as innovations in format and content, including through mixed use of different media, and recognise that the sector generates innovation through creative skills, new ways of working, new business models, and new forms of co-production (Qiu, 2020, Dillette and Ponting, 2021).

In December 2019, the Ministry of Culture signed a cooperation agreement on the compilation of the satellite account of creative industries of the Slovak Republic between the Slovak Statistical Office and the Ministry. The contract is concluded for a definite period until 31 March 2024. In the second half of 2019, it developed cooperation with the Ministry of Culture of the Czech Republic. The ministry has launched a new international project from August 1, 2019, called Animation League for Increased Cooperation in Europe (A.L.I.C.E. for short) under the Interreg Europe programme. The Ministry is working with five partners on the project Belgium, Italy, France, Spain and Poland. The outputs of the project will be the basis for supporting the development of the animation industry in Slovakia.

In October, the Ministry of Culture established a Platform for Cultural and Creative industry. The aim is to bring the activities of the $\mathrm{CI}$ as well as the activities themselves closer to the general public (Wisniewska and Czajkowski, 2019). At the same time, the ambition is to provide a space for the exchange of information between CI actors. It has started the implementation of the processes related to the preparation of the Analysis and Recommendations for the development of the creative industries in Slovakia (hereinafter referred to as 'the analysis') carried out within the framework of the Structural Reform Support Programme. This support is provided by the EC, which at the beginning of the year carried out the public procurement of the contractor of the Analysis. The contractor was KEA European Affairs, an international research centre. The analysis and recommendations will also be used as input to the forthcoming strategic documents in the sector of Creative industries.

In the framework of public policy-making activities aimed at the development of CIs, the following activities will be carried out activities related to the preparation and finalisation of the Action Plan for the development of Cultural and Creative Industries 2020-2021 as one of the main outputs of the international CREADIS3 project, Smart and Creative Regions. The Ministry in cooperation with members of a working group composed of representatives of public and private institutions, has developed an action plan containing the following actions/tasks:

1. Improving the quality of interventions in relation to CIs at national level,

2. Supporting the development of regional CI policies,

3. Creation of a new CI development strategy document.

The Action Plan was submitted for approval to the Minister of Culture of the Slovak Republic, who on 11 December 2019, at a management meeting, the Minister of Culture approved the proposal. This approval process is in line with the guidance of the Regional Government of the Basque Country (the main project partner responsible for guiding all the processes involved in the implementation of the project) approved by the Secretariat. The 
implementation period is planned for 2020 to 2021 . The action plan will be evaluated and the results will be used as a basis for the development of future strategic documents.

In 2020, subsidies were provided within the subsidy system of the Ministry of Culture provided subsidies through five programmes (defined at the element level in the programme structure) in the form of current or capital expenditures. A wide range of activities were supported, including the restoration of national cultural monuments, support for the activities of disadvantaged groups of population, promotion of attendance at cultural activities by primary and secondary school students, support for local and regional culture, and elimination of Covid-19 consequences on the creative industries. The total budget of funds allocated under the subsidy system in 2020 amounted to EUR 15,996,097. With adjustments to the budget in 2020, the original approved volume was adjusted to a total amount of EUR 21,563,722. Actual uptake of EUR 15808 420, representing 73.3\% of the adjusted budget (Eurostat, 2021b). Approximately 2,630 applications were submitted within the individual programs and sub-programs of the subsidy system, and more than 1,400 projects were supported.

According to the Ministry of Finance's data, the 2019 public consolidated expenditures on culture in Slovakia amounted to EUR 623 million. The amount of public funds allocated to culture oscillated over time around the average value of $1.71 \%$ of the public budget. The greatest portion of non-consolidated public expenditures on culture goes to the Ministry of Culture (41\%), more than one tenth goes to municipalities (21\%), RTVS (17\%), and higher territorial units (11\%). The expenditures of the Ministry of Culture hit EUR 351 million in 2019. The largest allocation went to the cultural heritage policy which received EUR 100 million, then the policy for the support of arts which got EUR 73 million, and the media and audiovisual policy obtained EUR 65 million. The church policy was allocated EUR 48 million and the general cultural policy of the Ministry of Culture amounted to EUR 44 million. The expenditures consumed by the operation of the Ministry totalled EUR 21 million.

The expenditures of the Ministry of Culture were allocated mainly to 30 budgetary and contributory organisations of the Ministry, accounting for $55 \%$ of the total spending. At the same time, the Ministry of Culture uses direct transfers to support churches (16\%), RTVS (11\%) and independent funds supporting arts and culture (6\%) (Figure 1). Subsidies and other transfers of the Ministry account for $8 \%$ and the expenditures of the Ministry of Culture itself consume only 5\% (Ministry of Finance, 2021).

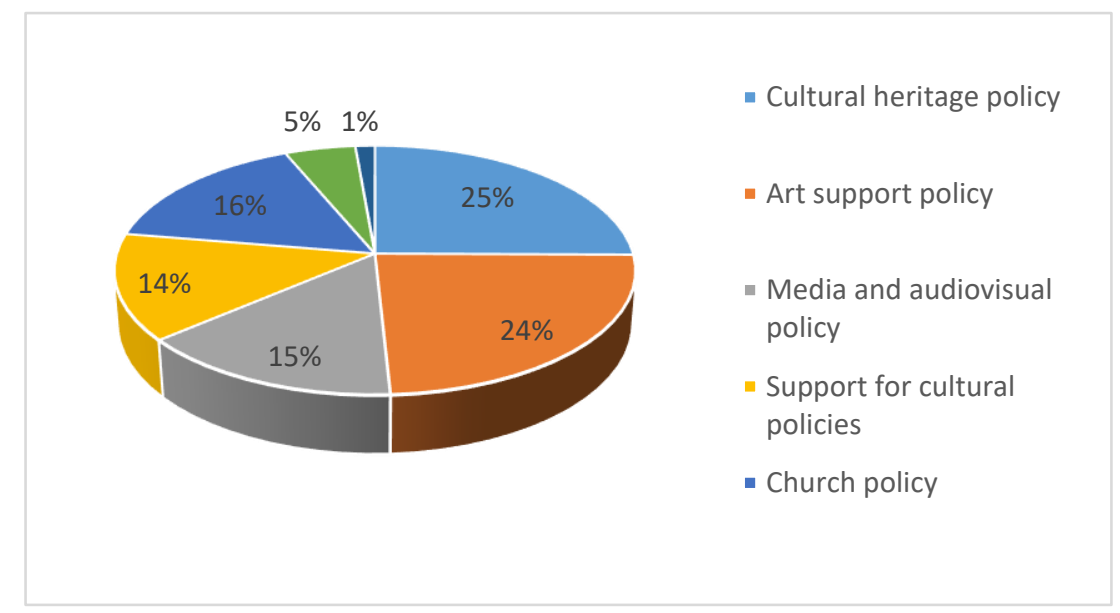

Figure 1. Expenditure's Structure - Ministry of Culture

Source: author's calculations according to Ministry of Finance (2021) 


\section{Methodology and Methods}

In this chapter, we described the main research aim and methodology used to fulfil the set aim.

\subsection{Research aim}

The aim of this paper is to measure the Covid-19 impacts on the Creative industries in Slovakia and evaluate the economic compensation suffered from the Ministry of Culture of the Slovak Republic. The current economic situation of the creative industries will be analysed according to the financial support policy in Slovakia. In the paper, we articulated the following research question and hypothesis:

- Research question no. 1: Is the financial support policy of the Ministry of Culture sufficient?

- Hypothesis ${ }_{1}$ : The expenditures of the Ministry of Culture ensure the growth of the Creative industries in Slovakia.

\subsection{Methodology of the research}

Our calculations on the extent to which the creative industries (CIs) and its sub-markets are affected by the COVID-19 pandemic are based on data from the Statistical Office of the Slovak Republic (sales tax statistics) and the Ministry of Finance. We continuously monitored and categorized the reporting on the impact of the COVID-19 pandemic on the CIs and its sub-markets. We analysed these data and assigned the findings to the individual CIs sectors.

To predict the expenditures of the Ministry of Culture, we constructed the basic scenario (BS), which is an analytical instrument used to calculate future expenditures without taking additional measures. The savings or additional expenditures resulting from the review calculated compared with the basic scenario express the volume of funds in excess or possible savings compared with the scenario, provided that no new decisions are made.

The BS for 2020 to 2023 is based on the actual expenditures of 2019. The expenditures related to the compensation of employees are indexed to the expected growth of wages in future; the expenditures related to the purchase of goods and services are indexed to the expected inflation. The basis of capital expenditures relies on the average expenditures during $2017-2019$ at the 2019 prices. They are then indexed to the expected growth of tax revenues, i.e. to the combination of the GDP growth and elasticity of tax revenues.

\section{Results and Discussion}

he Ministry of Culture supports individual cultural areas directly, by financing the ministerial budgetary and contributory organisations active in cultural areas and by paying contributions for RTVS and the News Agency, or indirectly through the Ministry of Culture's subsidy mechanism and independent funds supporting culture. The expenditures of the Ministry of Culture including transfers to funds and other entities, and the expenditures of local governments on culture are summed up under the basic scenario (Table 1). At the same time, this scenario estimates the expenditures on individual policies in $2021-2023$, provided that the policies are not changed. 
Table 1. Expenditure of the Ministry of Culture - predictions

\begin{tabular}{lrrrrrrrrrr} 
& AS & AS & AS & B & BS & B & BS & B & BS & BS \\
& $\mathbf{2 0 1 7}$ & $\mathbf{2 0 1 8}$ & $\mathbf{2 0 1 9}$ & $\mathbf{2 0 2 0}$ & $\mathbf{2 0 2 0}$ & $\mathbf{2 0 2 1}$ & $\mathbf{2 0 2 1}$ & $\mathbf{2 0 2 2}$ & $\mathbf{2 0 2 2}$ & $\mathbf{2 0 2 3}$ \\
\hline $\begin{array}{l}\text { State budget and other sources } \\
\text { (in mil. } \boldsymbol{~} \text { ) }\end{array}$ & $\mathbf{2 5 6}$ & $\mathbf{2 9 4}$ & $\mathbf{3 4 7}$ & $\mathbf{3 0 4}$ & $\mathbf{3 3 8}$ & $\mathbf{3 0 2}$ & $\mathbf{3 3 9}$ & $\mathbf{3 0 3}$ & $\mathbf{3 5 0}$ & $\mathbf{3 6 2}$ \\
Cultural heritage policy & 72 & 77 & 88 & 76 & 96 & 74 & 85 & 74 & 88 & 91 \\
Art support policy & 60 & 63 & 73 & 65 & 71 & 65 & 80 & 65 & 83 & 87 \\
Media and audiovisual policy & 42 & 50 & 65 & 48 & 49 & 48 & 50 & 48 & 52 & 53 \\
Support for cultural policies & 27 & 45 & 53 & 48 & 49 & 48 & 49 & 48 & 49 & 50 \\
Church policy & 44 & 46 & 48 & 52 & 52 & 52 & 54 & 52 & 56 & 58 \\
Conceptual and management & & & & & & & & & & \\
activities & 9 & 10 & 16 & 13 & 17 & 13 & 17 & 13 & 18 & 18 \\
IT funded from the state budget & 2 & 4 & 5 & 2 & 4 & 2 & 4 & 2 & 4 & 5 \\
Municipalities and higher & $\mathbf{2 1 7}$ & $\mathbf{2 5 1}$ & $\mathbf{2 7 8}$ & $\mathbf{-}$ & $\mathbf{2 8 3}$ & $-\mathbf{2 9 4}$ & - & $\mathbf{3 1 4}$ & $\mathbf{3 3 4}$ \\
territorial units & $\mathbf{4 7 4}$ & $\mathbf{5 4 5}$ & $\mathbf{6 2 5}$ & $\mathbf{3 0 4}$ & $\mathbf{6 2 0}$ & $\mathbf{3 0 2}$ & $\mathbf{6 3 3}$ & $\mathbf{3 0 3}$ & $\mathbf{6 6 5}$ & $\mathbf{6 9 6}$ \\
\hline Total & & & & & & & & & &
\end{tabular}

Source: author's calculations according to Ministry of Finance of the Slovak Republic (2021)

Table 2 includes the results of the regression analysis. The results rejected the Hypothesis 1, coefficient Sigma $(0,077)$ is higher than 0,05 . The expenditures of the Ministry of Culture don't ensure the growth of the Creative industries in Slovakia. The number of entities in the Creative industries has not been linked to the government expenditures and financial support (Eurostat, 2021a, Eurostat, 2021c).

Table 2. Results of regression analysis

Model Summary (Employment)

\begin{tabular}{|c|r|r|r|}
\hline$R$ & $R$ Square & Adjusted $R$ Square & Std. Error of the Estimate \\
\hline \hline 58 &, 34 &, 26 & 6,19 \\
\hline
\end{tabular}

ANOVA (Employment)

\begin{tabular}{|l|r|r|r|c|c||}
\hline & Sum of Squares & $d f$ & Mean Square & $F$ & Sig. \\
\hline Regression & 157,49 & 1 & 157,49 & 4,11 &, 077 \\
Residual & 306,43 & 8 & 38,30 & & \\
Total & 463,92 & 9 & & & \\
\hline
\end{tabular}

Coefficients (Employment)

\begin{tabular}{|c|c|c|c|c|c|c|c|}
\hline & \multicolumn{2}{|c|}{$\begin{array}{l}\text { Unstandardized } \\
\text { Coefficients }\end{array}$} & \multirow{2}{*}{$\begin{array}{c}\begin{array}{c}\text { Standardized } \\
\text { Coefficients }\end{array} \\
\text { Beta }\end{array}$} & \multirow[b]{2}{*}{$t$} & \multirow[b]{2}{*}{ Sig. } & \multicolumn{2}{|c|}{$\begin{array}{c}95 \% \\
\text { Confidence } \\
\text { Interval for B }\end{array}$} \\
\hline & $B$ & $\begin{array}{c}\text { Std. } \\
\text { Error }\end{array}$ & & & & $\begin{array}{l}\text { Lower } \\
\text { Bound }\end{array}$ & $\begin{array}{l}\text { Upper } \\
\text { Bound }\end{array}$ \\
\hline (Cons & 44,62 & 10,07 & , oo & 4,43 & ,002 & 21,40 & 67,85 \\
\hline Expenditures & ,04 & ,02 &, 58 & 2,03 & ,077 &,- 01 & ,09 \\
\hline
\end{tabular}

Source: author's calculations

Depending on the administrative form and the spread of COVID-19, the types and extent of measures vary across the different countries. Many actors in the CIs benefit from various superordinate programmes, that support companies and freelancers in general. These programs typically comprise: 
- Income support measures for self-employed and freelancers - provided by Ministry of Labour, Social Affairs and Family,

- State loans/guarantees for companies - provided by Ministry of Economy,

- Income subsidies for employees - provided by Ministry of Labour, Social Affairs and Family,

- Tax deferrals - provided by Ministry of Finance,

- Subsidies for self-employed persons - provided by Ministry of Labour, Social Affairs and Family,

- Grants for affected companies in Creative industries - provided by Ministry of Culture.

\section{Conclusions}

Culture which uses public funds in the areas characterised by market failure and private finance in the areas with a well-working market mechanism is the gold standard of culture funding in other countries.

The economic reason why culture is supported from public funds consists in the creation of public goods and positive externalities which otherwise would not come to existence or, at least, not in such a quantity only through interplay of market forces if they did not receive public support (Seraphin and Jarraud, 2021). Culture generates benefits both for individuals and the entire society. The public sector should take part in funding of those public cultural goods, the consumption of which supports attainment of national objectives, such as increasing tolerance, solidarity or national identity. The amount used for the support should reflect social benefits of the relevant goods, which is something that is not reflected in their market value. The hypothesis 1 was rejected, the null hypothesis was accepted. The financial support for the creative industries is insufficient and does not ensure the growth of the Creative industries in Slovakia.

\section{Acknowledgements}

This paper is the output of the scientific grant VEGA n. 1/0340/19 "The Entrepreneurial Dimension of Creative industries in the Context of Innovation and Smart Growth (100\%).

\section{References}

1. Bartik, A. W., Bertrand, M., Cullen, Z., Glaesar, E. L., Luca, M., \& Stanton, C. (2020). The impact of COVID-19 on small business outcomes and expectations. Proceedings of the National Academy of Sciences, 117(30), 17656-17666.

2. Beland, L., Fakorede, O., \& Mikola, D. (2020). Short-term efect of COVID-19 on selfemployed workers in Canada. Canadian Public Policy, 46(S1), S66-S81.

3. Dillette, A., \& Ponting, S. S. A. (2021). Diffusing innovation in times of disasters: considerations for event management professionals. Journal of Convention \& Event Tourism, 22(3), 197-220.

4. Eurostat. (2021, August 10)a. Cultural employment by NACE REV. 2 activity. https://ec.europa.eu/eurostat/databrowser/view/cult_emp_n2/default/table?lang=en

5. Eurostat. (2021, August 10)b. General government expenditure by function (COFOG). https://ec.europa.eu/eurostat/databrowser/view/gov_10a_exp\$DV_578/default/table?la $\mathrm{ng}=\mathrm{en}$. 
6. Eurostat. (2021, August 10)c. Number and average size of enterprises in the cultural sectors by NACE Rev. 2 activity. https://ec.europa.eu/eurostat/databrowser/view/cult_ent_num/default/table?lang=en

7. Krajnovic, A., Raguz, I. V., \& Perkovic, A. (2021). Strategic and digital marketing in cultural institutions and the impact of the covid-19 pandemic - A comparative analysis of two case studies. Interdisciplinary Description of Complex Systems, 19(2), 257-280.

8. McKibbin, W. \& Roshen, F. (2021). The Global Macroeconomic Impacts of COVID19: Seven Scenarios. Asian Economic Papers, 20 (2), 1-30.

9. Ministry of Finance of the Slovak Republic. (2021, August 9). Culture. https://www.mfsr.sk/en/finance/value-money/spending-reviews/culture-2019/.

10. Mont, O., Curtis, S. K., \& Palgan, Y. V. (2021). Organisational Response Strategies to COVID-19 in the Sharing Economy. Sustainable Production and Consumption, 28, 5270.

11. Palrao, T., Rodrigues, R. I., \& Estevao, J. V. (2021). The role of the public sector in the aftermath of the COVID-19 pandemic crisis: The case of Portuguese events' industry. Journal of Convention \& Event Tourism.

12. Pankov, S., Schneckenberg, D., \& Velamuri, V. K. (2021). Advocating sustainability in entrepreneurial ecosystems: Micro-level practices of sharing ventures. Technological Forecasting and Social Change, 166, Article 120654.

13. Seraphin, H., \& Jarraud, N. (2021). COVID-19: Impacts and perspectives for religious tourism events. The case of Lourdes Pilgrimages. Journal of Convention \& Event Tourism.

14. Qiu, W. (2020). The pandemic and its impacts. Health, culture and society, 9, 1-11. http://dx.doi.org/10.5195/HCS.2017.221

15. Wisniewska, A. \& Czajkowski, M. (2019). Designing a socially efficient cultural policy: the case of municipal theaters in Warsaw. International Journal of Cultural Policy, 25(4), 445-457. ISSN 1477-2833. 